\title{
Frameworks for embedding a research culture in allied health practice: a rapid review
}

\author{
Susan C. Slade ${ }^{1 *}$, Kathleen Philip ${ }^{2}$ and Meg E. Morris ${ }^{1,3}$
}

\begin{abstract}
Background: Although allied health clinicians play a key role in the provision of healthcare, embedding a culture of research within public and private health systems remains a challenge. In this rapid review we critically evaluate frameworks for embedding research into routine allied health practice, as the basis for high quality, safe, efficient and consumer-focused care.
\end{abstract}

Methods: A rapid review (PROSPERO: CRD42017075699) was conducted to evaluate frameworks designed to create and embed research in the health sector. Included were full-text, English-language, peer-reviewed publications or Government reports of frameworks that could inform the implementation of an allied health research framework. Eight electronic databases and four government websites were searched, using search terms such as models, frameworks and research capacity-building. Two independent researchers conducted all review stages and used content and thematic analysis to interpret the results.

Results: Sixteen framework papers were finally included. Content analysis identified 44 system and regulatory level items that informed the research frameworks, 125 healthcare organisation items and 76 items relating to individual clinicians. Thematic analysis identified four major themes. Firstly, sustainable change requires allied health research policies, regulation, governance and organisational structures that support and value evidence-based practice. Secondly, research capability, receptivity, advocacy and literacy of healthcare leaders and managers are key to successful research implementation. Third, organisational factors that facilitate a research culture include dedicated staff research positions, time allocated to research, mentoring, professional education and research infrastructure. When healthcare agencies had strong partnerships with universities and co-located research leaders, research implementation was strengthened. Finally, individual attributes of clinicians, such as their research skills and capabilities, motivation, and participation in research teams, are essential to embedding research into practice.

Conclusion: Theoretical frameworks were identified that informed processes to embed a culture of allied health research into healthcare services. Research-led and evidence-informed allied health practice enables optimisation of workforce capability and high-quality care.

Keywords: research capacity, allied health, policy, systematic review knowledge translation, implementation science, leadership

\footnotetext{
* Correspondence: s.slade2@latrobe.edu.au

${ }^{1}$ La Trobe Centre for Sport and Exercise Medicine Research, School of Allied

Health, College of Science, Health \& Engineering, La Trobe University,

Bundoora 3086, Australia

Full list of author information is available at the end of the article
} 


\section{Background}

Allied health services are a major pillar of health and social care worldwide and allied health professionals constitute approximately one-third of the health workforce [1]. The term 'allied health' refers to a broad range of health disciplines, excluding doctors, nurses and midwives, dentists, and complementary therapists. Allied health can include disciplines such as physiotherapy, speech therapy, occupational therapy, podiatry, psychology, dietetics, pharmacy, prosthetics, orthotics, orthoptics, radiology, medical science, social work and exercise physiology [2], although this varies across the globe.

Allied health clinicians play a key role in promoting health and wellbeing in the public and private healthcare sectors [3]. As well as managing impairments, disabilities and participation restrictions [4], allied health professionals bridge the gap between the medical and nursing professions, advocate for patients and their families, and foster inter-professional teams and multi-disciplinary care [1, 2, 4-8]. Allied health professionals are encouraged to be research literate [6], and to assist the translation of research evidence into clinical practice to optimise patient outcomes [9]. Some are also research generators [10] and others focus on research implementation [11] to bridge the evidence-practice gap [12].

Evidence-based practice is central to effective, efficient, consumer-focused healthcare. It centres around the principles of (1) best available evidence, (2) clinical expertise and (3) incorporating consumer preferences into practice [13]. Despite clinical expertise and a quality focus, some allied health professionals lack research and evaluation skills [14-16]. Clinical practice has traditionally been directed towards patient care and resource allocation, with allied health clinicians being 'consumers' of research [6]. This is evolving, and more allied health professionals are now becoming involved in research training, knowledge generation, knowledge translation, evidence implementation, policy setting, research partnerships, co-production and research leadership $[1,2,7,10,17,18]$.

Underpinning evidence-based practice is a strong research culture with a framework that enables service planning, decision-making and sustained integration of evidence-based healthcare [19-21]. Governments have increasingly recognised that resources are optimised and health outcomes are improved when health policy and programme design are informed by evidence from research [22-24]. A functioning research culture is necessary to enable this research generation [9]. There is a need for research capacity-building in allied health to develop individuals to higher levels of skill, which will enable them to conduct quality research and translate the findings to improve patient outcomes.

There also exists a need to improve the ability of individuals, organisations and systems to conduct, use and promote research through providing training, funding, infrastructure, linkages and career pathways [18, 25-27]. Some of the main reasons for building research capacity and a research culture are to adopt evidence-based practice, generate new knowledge, achieve research objectives, strengthen workforce research literacy and assist workforce recruitment, retention and job satisfaction [12, 18, 20, 28, 29].

A strategic approach to research capacity-building is needed to accommodate the complex and multidisciplinary context of allied healthcare $[1,8,30]$. The strategies that have been traditionally used to build research capability and capacity have mainly focused on processes, such as skill development, in evidencebased practice, journal clubs or quality projects $[1,2$, $6,19,31,32]$. They have also focused on research training, such as grant writing, conference presentations, publication writing, and encouragement to participate in research networks and partnerships $[5,28$, 33-40]. Despite the need, there is no current framework for embedding an allied health research culture across allied health practice in public or private healthcare systems.

As the basis for developing a future policy framework to embed allied health research into routine clinical practice, this review shall critically evaluate the published worldwide literature on theories and frameworks that have been designed and developed to create and embed research capacity in the allied health clinical sector. A framework provides (1) the lens through which research capacity-building strategies are developed and evaluated; (2) the potential determinants and domains of research implementation (including individual, organisational and policy factors); (3) research engagement actions; and (4) mechanisms for research to inform policy and practice $[22,26]$.

Of particular interest in this review were frameworks to build research capability, capacity and implementation. We also searched for frameworks that incorporated a broader systems level and policy viewpoint so that research implementation did not solely rest in the hands of individual clinicians. We propose that allied health clinical practice can be enhanced by embedding a research culture into routine service provision within the clinical environment. The implementation of policies, systems, environments and leadership models empowering clinicians to incorporate research as a routine part of their role were also foci of this rapid review. 


\section{Research question}

What allied health research frameworks and models have robust evidence to enable a research culture to be embedded into routine allied health clinical practice?

\section{Aims}

This review shall inform the future design of an allied health framework to foster a culture of research in allied health practice. As a first step, the primary aims of this rapid review are to (1) identify existing research capacity-building and capability-building and research culture frameworks/models, as well as to (2) synthesise existing evidence to identify the essential elements for embedding a culture of research within allied health practice. The secondary aim is to summarise the strengths and limitations of existing frameworks and models.

\section{Methods}

This rapid review was commissioned by the Department of Health and Human Services, Victoria, Australia, and was registered with the international prospective register of systematic reviews (PROSPERO: CRD42017075699). The rapid review was conducted and informed by Cochrane guidelines [41] and rapid review methods [42, 43], and reported according to the Preferred Reporting Items for Systematic Reviews and Meta-Analyses (PRISMA) Statement [44] and the Enhancing Transparency in Reporting the synthesis of Qualitative research [45]. The a priori inclusion and exclusion criteria were established before conducting searches of the electronic databases and were applied to the final search yield. All review stages were conducted by two independent reviewers, who collaborated when necessary to reach consensus.

\section{Eligibility criteria}

Eligibility criteria were established before searching electronic databases. Papers were included if they were full text English-language, published in peerreviewed journals or on organisation/Government websites, reported frameworks, models for building research capacity and culture in healthcare, and provided items for review and/or evaluation. Broad healthcare models could be included for later evaluation of applicability to allied health. Editorials and opinion pieces were excluded.

\section{Definitions}

1. A 'Theory' was defined as "a system of ideas that provide an explanation and/or a set of principles on which the practice of an activity is based" [46]. It has also been defined as " $a$ set of analytical principles or statements designed to structure our observation, understanding and explanation of the world" [47].

2. A 'Model' was defined as " $a$ deliberate simplification of a phenomenon or a specific aspect of a phenomenon", "closely related to theory" and "a model is descriptive while a theory is explanatory" [47].

3. A 'Frameworks' was defined as "a structure, overview, outline, system or plan consisting of various descriptive categories, e.g. concepts, constructs or variables, and the relations between them that are presumed to account for a phenomenon" [47]. In this review, we considered that a framework would inform polices, decisions and judgments about evidence-based allied health practice. The framework could also specify potential individual, system and organisational determinants of research use, research engagement and knowledge dissemination [22].

4. 'Research capacity-building' was defined as the "process of individual and institutional development which leads to higher levels of skills and greater ability to perform useful research" [26]. Key common elements across research capacity-building include shared goals, collaboration and partnership, education and training, organisation support and leadership, evaluation, and monitoring. It may be considered as a continuum of clinician research development from a research consumer to a research active clinician and then to a research leader. It is an approach to the development of sustainable skills, organisational structures, resources and commitments to improvement in health and other sectors to multiply health gains [26].

\section{Identification of included papers}

Electronic databases were searched without date limits up until October 15, 2017, using explosions and combinations of key search terms such as allied healthcare, allied health clinicians, allied health, framework, model, theory, research capacity, capacity-building, research capacity-building, research culture, clinical research, research culture, organisational role, motivation theory, health researcher, framework, theory, model, policy, allied health, translation, implementation, leadership, and governance. A sample MEDLINE search strategy is included in Appendix 1.

The following eight databases were searched: CINAHL, Embase, MEDLINE, PubMed, PsychInfo, Health and Psychological Instruments, Global Health and Google Scholar. Websites included the Government of Canada Publications, United Kingdom Department of Health, Victorian Government Library Services catalogue, the Primary Health Care Research and Information Service, and Australian Government 
health websites. Reference lists of relevant reports were searched, and other relevant work sought through citation tracking, the grey literature, consultation with the Research and Liaison Librarian at the Victorian Government Library Service and contact with content and research experts. All of the searches were downloaded to a reference database for deletion of duplicates and initial screening of titles by the primary author, who deleted those that were clearly irrelevant.

Two reviewers independently reviewed the search results, deleted duplicates, and screened titles and abstracts for exclusion of reports that did not meet the eligibility criteria. Full text copies were obtained for all potentially relevant reports, independently screened against the eligibility criteria and read in full before final inclusion/exclusion.

\section{Method quality appraisal}

Method quality appraisal was conducted when there was a validated instrument for the appropriate empirical study design such as the preliminary Mixed Methods Appraisal Tool (MMAT) [48] for mixed methods studies or the Critical Appraisal Skills Programme (CASP) Checklist [49] for qualitative empirical studies. In the absence of a validated instrument we described the reported psychometric properties or provided a narrative summary of elements that may have contributed to the risk of bias. We used guidance from the National Collaborating Centre for Methods and Tools [50].

\section{Data extraction}

Data extraction guidelines were developed so that the same information was extracted from each included paper and systematically extracted into spreadsheets under the pre-specified headings of first author, title, year, journal or organisation or publisher, domain, theory, model, items, and the conceptual framework. Items were extracted independently by two researchers from each framework or from the text of the report. The research capacity-building titles were identified and their items were assembled into groups that addressed common targets. Common targets included headings that incorporated words such as individual, organisation, system or policy. Under these headings we included items such as enablers, barriers, skills, self-efficacy, policies and procedures, management, legislation, regulation, etc. The completed data extraction forms were examined for consistency. Following discussion, these were merged for the data synthesis phase.

\section{Data synthesis}

Two independent reviewers (SS, MM) conducted thematic and content analysis and consulted during the process using the constant comparison method, which (1) summarising and synthesising the item content with data reduction of items into 'like' categories and (2) the formation of themes through overarching similarities and connections. No prior theory was used to assist in identification of items and frameworks, but rather iterative rounds of open data-driven inductive coding were used [51-53]. The content analysis aimed to identify the key items that were important for embedding a research culture. The thematic analysis aimed to build an understanding of the broader framework of research capacity-building.

\section{Results}

The total search yield of 1255 articles was sorted by title and 1158 clearly unsuitable titles were excluded. Five papers were added from reference lists and the remaining 97 titles were examined by title and abstract. Sixty-eight papers were excluded after applying the eligibility criteria to the information contained in the abstract. Of the remaining 34 papers, two reviewers independently, and by consensus, excluded 23 papers after reading them in detail and applying the eligibility criteria.

Figure 1 shows a flowchart of progress into the review, indicating the papers/documents that met the criteria and were included for data extraction, as well as the final exclusions. The final 16 included papers and organisation/government reports contained 16 discrete research capacity-building frameworks and models that included domains and items for data extraction and synthesis (Table 1) $[19,22-28,30,54-$ 60]. Twenty-three papers were excluded in the final round; 18 did not report a framework or model, one was a conference abstract, and four were qualitative or investigative studies (Appendix 2). Frameworks for research capacity-building in healthcare had been developed and implemented in Australia, Canada, United Kingdom and United States of America and date from 2001 to 2017. The extracted frameworks are summarised in Table 1.

\section{Method quality appraisal}

Due to a lack of reported data, we were unable to apply the MMAT and CASP checklists to 10 of the included frameworks. Five of these frameworks were derived by expert opinion and evidence synthesis and will require validity and reliability testing [19, 26, 30, 55, 57]. Three frameworks were derived from literature reviews and unreported qualitative/quantitative methods $[28,56,60]$. Two frameworks were government reports and guidance 


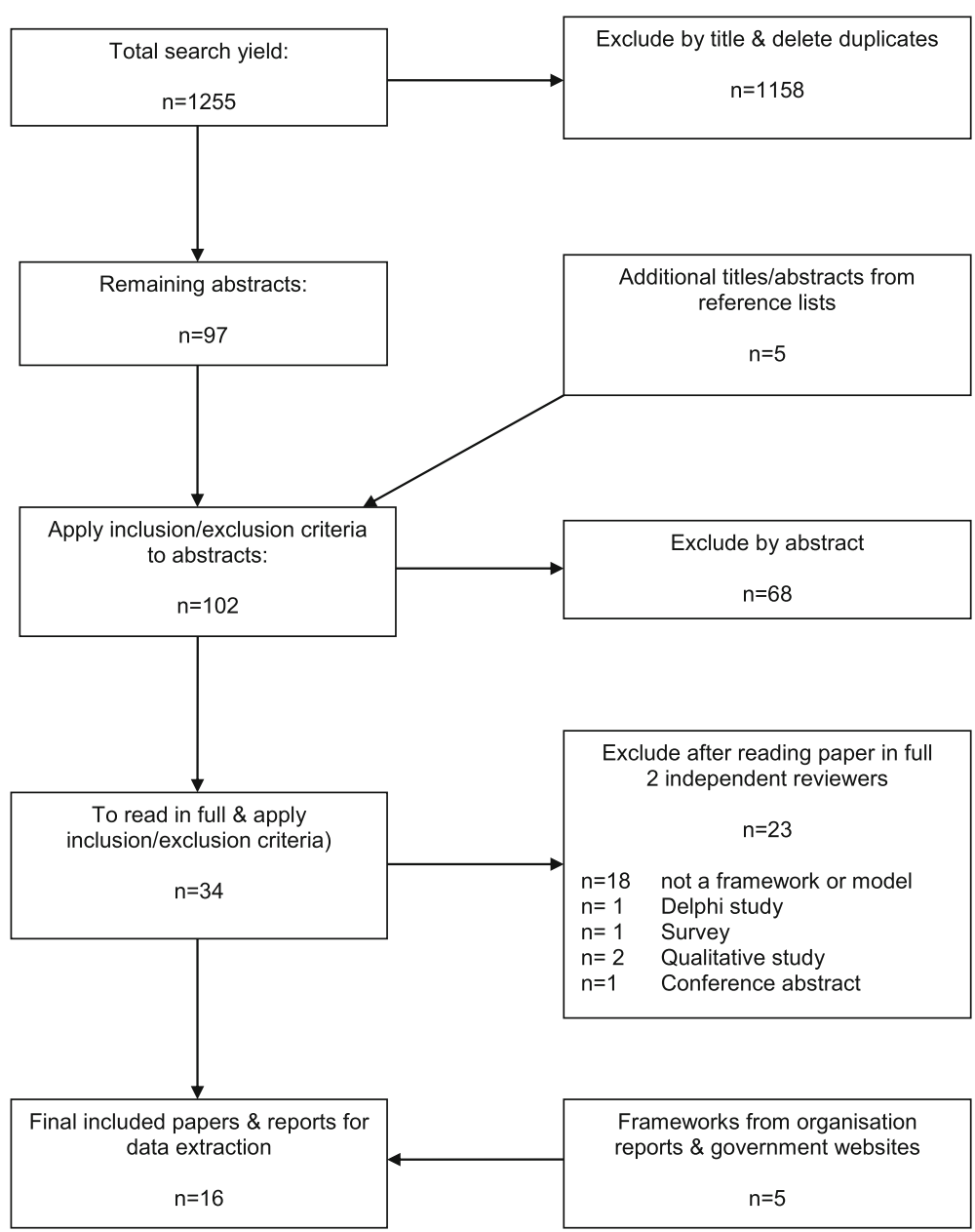

Fig. 1 PRISMA-compliant flowchart for inclusion into the review

documents derived from expert opinion and required implementation and effectiveness testing [23, 24].

The SPIRIT Action Framework was developed by literature synthesis, interviews with policy-makers and an iterative process of pragmatic tool development. The SPIRIT is not specific to allied health and requires implementation and effectiveness testing for allied health professions. It can guide conceptually informed practical decisions in the selection and testing of interventions to increase the use of research in policy. It scored $100 \%$ on the MMAT Appraisal Tool for quality of qualitative and mixed methods [22].

The Thematic Model for Research Capacity Building was informed by qualitative research methods using structured interviews that were thematically analysed. Four key themes formed the foundation of a research capacity-building framework. It scored $100 \%$ on the MMAT for the quality of the qualitative methods and satisfied all components of the CASP [25].

The Wenger's Community of Practice Model was informed by qualitative research methods using focus groups that were thematically analysed. It scored $100 \%$ on the MMAT for the quality of the qualitative methods and satisfied all components of the CASP [26].

The SEER Framework was informed by literature synthesis, item generation and refinement, consultation with policy-makers, and testing of measurement properties. It demonstrated good internal consistency and reliability but was not specific to allied health. The four included scales may be used in policy settings to evaluate current capacity and identify areas that need capacity-building. It scored $100 \%$ on the MMAT Appraisal Tool for quality of mixed methods [54].

The Research Capacity and Culture tool was developed by a literature review and evidence synthesis. Psychometric testing in a Queensland primary healthcare sample $(n=134)$ demonstrated excellent internal consistency for organisation, team and individual domains, and strong test-retest reliability. The Research Capacity and Culture tool was not specifically designed for allied health alone and requires translation and effective testing. It scored $100 \%$ on the MMAT 


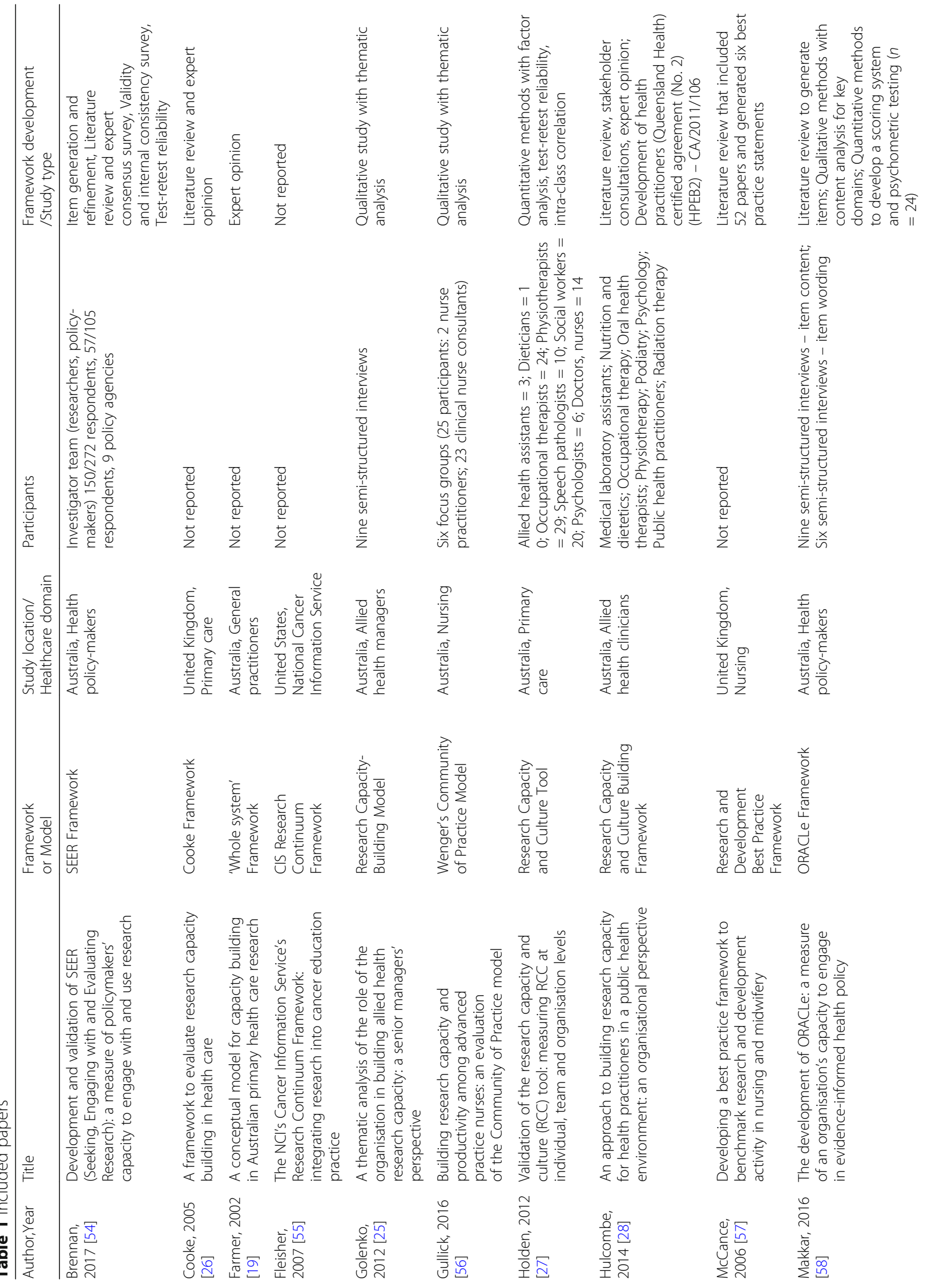




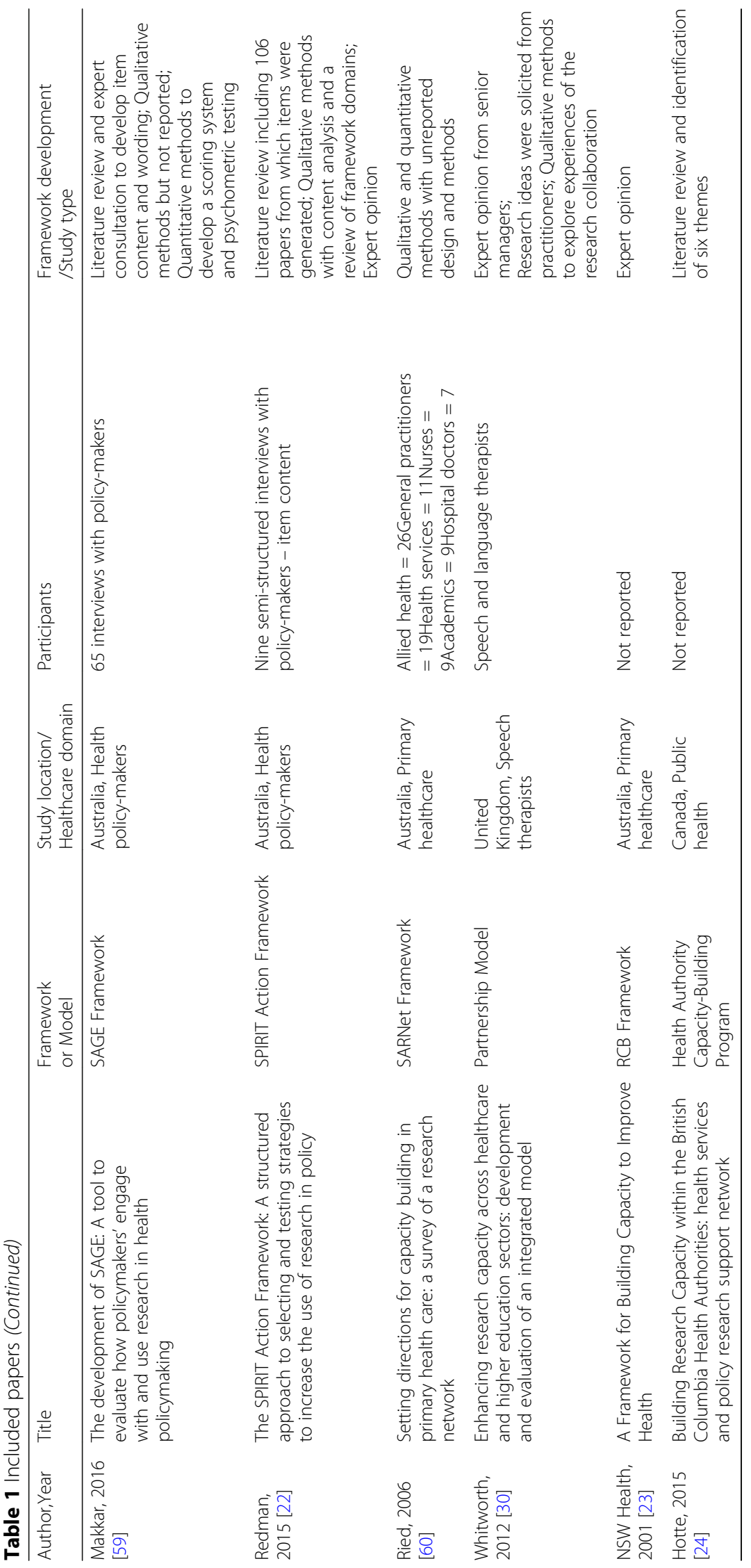


Appraisal Tool for quality of descriptive quantitative methods [27].

The ORACLE Framework was derived by robust mixed methods that included qualitative methods for face validity and quantitative methods for scoring a matrix. It was designed to score the capacity of an organisation to use research in policy-making but is not specific to allied health. It has yet to be validated as a measure of organisational capacity and culture to support research use. It scored $100 \%$ on the MMAT Appraisal Tool for quality of qualitative, descriptive quantitative and mixed methods [58].

The SAGE Framework was derived by interviews with policy-makers and document analysis but the explicit qualitative methods were not described. It was designed to measure the extent to which research was engaged with and used in a discrete policy or programme document. It was not designed to identify overarching organisational structures that may contribute to barriers to research use and psychometric testing for validity and reliability is planned. It scored $100 \%$ on the MMAT Appraisal Tool for quality of descriptive quantitative and mixed methods [59].

\section{Content analysis}

A total of 260 items were extracted from the 16 frameworks and 15 duplicate items were deleted. From the remaining framework items, and from our data analysis and interpretation of these data, we identified the following three domains by consensus: (1) system or regulatory (44 items), (2) organisation (125 items) and (3) individual (76 items). Through an iterative review process and constant comparison, the items with similar content and meaning were grouped using the domain headings summarised in Fig. 2.

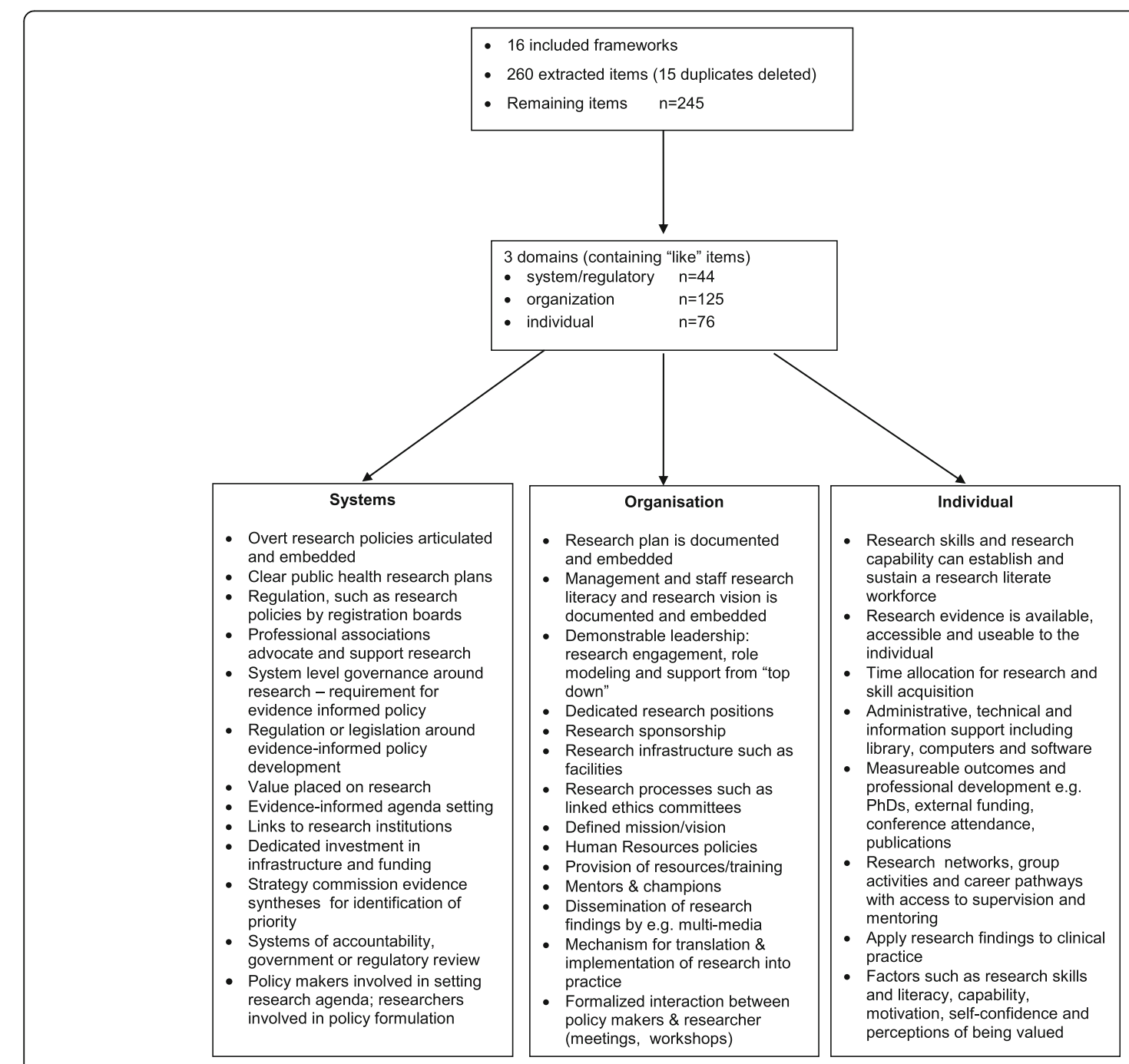

Fig. 2 Content analysis - item reduction of identified research capacity-building frameworks and models 


\section{Thematic analysis}

The main over-arching theme identified in this review was that provision of research-informed healthcare that is consistent with best available evidence requires over-arching high level policies to enable leadership, organisations and individuals to embed a research culture into everyday allied health practice. Four key themes were identified, as shown in Table 2 .

\section{Theme 1: Regulatory environment, governance and organisational structures}

All of the included frameworks provided descriptions of over-riding policies, governance frameworks and regulatory systems considered as essential for sustaining a culture of scientific enquiry and evidence-based practice $[15,18-24,26,50-56]$. These were applicable across the entire allied healthcare domain, as well as for medicine and nursing. Sustainable change was argued to require an environment that supports and values the development, and continuation, of research and evaluation processes $[19,22,25,27,57-59]$.

Evidence-informed policy-making needs to be understood and implemented, particularly the incentives for policy-makers to support the use of evidence in policy cycles [11, 28]. Strengthening the appreciation and capacity of individual policy-makers, and their organisations, to make greater use of evidence can be a first step in generating better evidence-

Table 2 Themes identified in the data analysis

\begin{tabular}{|c|c|}
\hline Theme & Title and summary \\
\hline $\begin{array}{l}\text { Overarching } \\
\text { theme }\end{array}$ & $\begin{array}{l}\text { The provision of research-informed healthcare that is } \\
\text { consistent with best available evidence requires } \\
\text { over-arching policies that enable the organisation and } \\
\text { individuals to be research active }\end{array}$ \\
\hline Theme 1 & $\begin{array}{l}\text { Regulatory environment, governance and organisational } \\
\text { structures. Sustainable change requires allied health } \\
\text { research policies, regulation, governance and } \\
\text { organisational structures that support and value } \\
\text { evidence-based practice }\end{array}$ \\
\hline Theme 2 & $\begin{array}{l}\text { Leadership and management buy-in• Research capability, } \\
\text { receptivity and literacy of healthcare leaders and managers } \\
\text { are key to successful research implementation }\end{array}$ \\
\hline Theme 3 & $\begin{array}{l}\text { Systems, tools, resources and time. The provision of } \\
\text { research infrastructure, research systems, tools, databases, } \\
\text { resources, time allocation, dedicated research staff } \\
\text { positions, mentoring, professional education and } \\
\text { mechanisms for recognition and reward are key } \\
\text { organisational factors that enable research capacity- } \\
\text { building. Partnerships between healthcare agencies } \\
\text { and universities with co-located research leaders } \\
\text { optimises research quality and productivity }\end{array}$ \\
\hline Theme 4 & $\begin{array}{l}\text { Attributes of individual clinicians. Attributes and } \\
\text { capabilities of individual clinicians such as research } \\
\text { qualifications, skills, research literacy, communication } \\
\text { skills, partnerships, confidence and motivation help } \\
\text { strengthen and develop research interactions and } \\
\text { increase research receptivity }\end{array}$ \\
\hline
\end{tabular}

informed policy. Policy-makers can be informed about, and benefit from, evidence-informed policy and can also be assisted by tools to help them to access, analyse and utilise evidence. They can be encouraged to engage more closely with researchers as policy advisors. Collaborations with, and skills acquisition by, policy-makers were reported as important factors that influence the use of research results and evidence [19, 22-27, 30, 54-60].

\section{Theme 2: Leadership and management buy-in}

Common to all frameworks were themes of research as the 'core business' with strong leadership and investment, by management, in evidence-informed policy and the acquisition of research literacy [19, 22-27, 30, 55-60]. There was also consensus that individual allied health clinicians could further benefit from active and deliberate support to enable them to progress from being a non-participant in research to becoming truly research active and evidence informed [23, 24, 30, 58-60]. Strong recommendations were made to embed formal engagement and collaboration with researchers and research institutions. The provision of well-resourced infrastructure and mission statements promoting research-informed policy and practice were advocated. Access to commissioned systematic or rapid reviews would generate research and inform policy development $[19,22-27,30,55-60]$. External regulation included government research institutes, health licensing boards and legislation, for example, United Kingdom National Institute of Clinical Excellence [61] and the Australian Health Practitioner Regulatory Agency [62].

\section{Theme 3: Systems, tools, resources and time}

All frameworks mentioned the importance of providing infrastructure, systems and processes to promote and support a culture of enquiry and evidence [19, 22-27, 30, 55-60]. A key organisational resource that was perceived to be enabling was clear and well documented research-related policies and procedures, including research responsibilities being explicit in all allied health job descriptions [22, 25, 27, 58, 59]. The guidelines for workforce recruitment and retention could include documenting career pathways with research components and assigning dedicated clinical research positions [12, 23, 24]. It also included allied health research being mapped in strategic plans $[19,25,27,59]$ and annual reports $[19$, $25,27,58,59]$. An in-house ethics committee or easy access to a local research ethics committee was also facilitatory [23, 24, 58, 59].

Human resources processes, such as mandatory quality and research training, were considered to be 
of benefit [26-28, 30, 54, 58-60]. The documentation of research outputs and research dissemination strategies, such as communities of practice, research committees, research seminars and research newsletters, were considered important $[19,23-27,30,54$, 58-60]. Infrastructure recommendations included the routine provision of information technology services and equipment supporting research, such as $24 \mathrm{~h}$ intranet access, library access on line, laptops and tablets, and access to statistical and bibliographic software [19, 23-28, 30, 54, 58-60]. Collaboration between the healthcare practice settings and an academic institute was also considered highly beneficial to research capacity-building $[19,23-28,30,54,58-$ $60]$. This could be formalised by joint research leadership appointments and industry research partnerships $[19,23-28,30,54,58-60]$.

\section{Theme 4: Attributes of individual clinicians}

There are important attributes and capabilities of individual clinicians that strengthen and develop research interactions and increase research receptivity. These include research skills and literacy, communication skills, confidence and motivation [26]. To be able to build research capacity, it is essential for the allied health workforce to be able to access, understand and apply research evidence $[19,23-28,30$, 54, 58-60].

To build research capacity it is also necessary for individual clinicians to strengthen and develop research partnerships, develop confidence and increase research receptivity $[19,23-28,30,54,58-60]$. Individuals need training to acquire research literacy $[25$, $27,28,30,54,58-60]$. They can also be enabled to become research active by having ready access to mentors, research champions and multidisciplinary research collaboration networks. Practical assistance can come in the form of training in scientific writing, conference presentations, public speaking skills, journal clubs and applying for research funding [19, $23-28,30,54,58-60]$. Individual recognition for research achievements through awards, incentives and promotion can also assist the adoption of researchled practice $[19,23-28,30,55,56]$.

\section{Discussion}

This rapid review identified 16 research capacitybuilding frameworks that could inform the policies, principles and design of systems for the embedding of a research culture into allied health clinical practice (Table 1). The data have been synthesised to identify essential elements for embedding a culture of research within allied health clinical practice. There were two key allied health-specific models -
Golenko's Thematic Model for Research Capacity Building [25] and Hulcombe's Health Practitioner Research Capacity and Culture Building Framework [28]. There was another that was specific to speech pathology [30] and two that were primary care and included allied health, medicine and nursing $[56,60]$. The frameworks highlighted the importance of highlevel systems, organisational governance and regulations that support and value allied health research. They also noted the importance of hospital leaders, and allied health managers in particular, being research literate and advocates of allied health research $[25,29]$.

Of value were explicit local systems and procedures for research conduct and regulation, including policies and procedures on research ethics, methods, consumer involvement, research documentation, data storage, and the dissemination of research findings to end users. Hulcombe et al. [29] stressed the importance of ensuring physical resources and time to support a research-informed workforce. The establishment of allied health research networks and formal partnerships with tertiary institutions, research institutes and industry partners also helped to embed a research culture within allied health $[12,20-22$, 54-60].

Overall, the key systems factors found in this review to support allied health research were the existence of allied health research policies together with government level advocacy, support and regulations $[19,22,25,28,30,31,54,56,58,63]$. Strengthening the research capabilities of individual policy-makers and assisting them and their organisations to make greater use of evidence was arguably a necessary first step in generating better evidence-informed policy $[25,27,54,55,57-59,63]$.

The key enabling organisational factors were leadership within organisations (especially allied health managers), collaboration, mentorship and resources. For allied health research capacity and culture to be developed and sustained, a whole-of-organisation approach was optimal $[19,25-28,54,56-60]$ and support from senior management was essential $[19,23-$ $28,54,56-60,63]$. Research can be incorporated into the organisational structure, processes and core business such as strategic plans and mission statements [26-28, 54, 57-60]. Systems that establish career pathways including research-active leadership positions, research champions, conjoint university positions and research literacy were viewed as helpful [12, 19, 26-28, 30, 54-56, 58, 59, 63].

At the organisational level, collaborations between healthcare practice settings and academic institutes such as universities were perceived to have major 
impact $[19,26-28,30,54-56,58,59]$. For change to be sustained, it was recommended that institutions provide incentives for adoption of evidence-informed behaviours [8, 39, 58, 59, 63]. An institutionalised method was preferable $[17,22,25-28,35,54]$ and could be achieved through an external regulatory body such as demonstrated by the United Kingdom National Institute of Clinical Excellence [61].

Common to all included frameworks were the themes of strong leadership and management investment. Strengthening the capacity of individuals and organisations is necessary but probably insufficient in isolation to ensure the sustainability of evidenceinformed policy-making. Strengthening of institutional capacity and regulatory control arguably requires resources, legitimacy and regulatory support from policy-makers [19, 22-28, 30, 54-60].

\section{Practice implications}

To support the development of research capacity and capability in allied health, policy-makers and healthcare organisations can optimise capabilitybuilding frameworks, models and strategies. The identification of approaches suited to the local environment, caseload mix and workforce profile facilitates implementation. Regulation, strong leadership and supportive management structures form essential elements of a successful research culture within allied health $[7,8,12,19,22-28,30,34,54-60]$. The future lies in new policies informed by a robustly derived framework.

\section{Limitations}

We made every effort to source hard-to-reach publications by using forward and backward citation tracking, government websites, hand-searching and expert communication. Nevertheless, some policy documents or publications not in Web of Science or SCOPUS may have been missed. Moreover, there are more than 20 allied health professions and the literature reviewed may not have addressed issues for each. The literature reviewed predominantly focused on physiotherapy, psychology, social work, podiatry, pharmacy, occupational therapy and dietetics.

Some of the included frameworks did not demonstrate robust development methods and some were government reports. There was a paucity of evidence to support the implementation of these particular capability and capacity-building models in clinical organisations and any measures of their impact or effectiveness. Despite the method quality limitations there was, however, a consensus across all frameworks on the fundamental domains and items. The conceptual relationships between the themes are beyond the scope of this rapid review and await further investigation.

\section{Conclusion}

This systematic review and critical evaluation of the literature identified 16 theoretical frameworks that could inform the development of models to embed a culture of allied health research into public and private healthcare services. The framework elements inform policy development, as well as the design of systems and linkages to support knowledge generation, research implementation and knowledge translation. The results will inform future allied health research capacity-building frameworks at government and policy level to oversee investment, evidence uptake and research implementation. The challenges facing policy-makers to support the use of evidence in policy cycles is considerable. Safer, more effective and efficient consumer-oriented care is the ultimate goal. Research-led and evidence-informed allied health practice also facilitates workforce recruitment, retention and capability.

\section{Appendix 1 \\ Example search strategy: Ovid MEDLINE (up until 15/10/ 2017)}

1. Capacity Building/ or ("capacity building" or "research capacity" or (system* adj2 capacit*) or (("research" or "allied health") adj5 capacit") or ((build* or increas* or develop* or enhanc* or strengthen* or "motiv*) adj5 (capacit* or skill* or abilit* or workforce)).ti,ab

2. Research/ or (culture or clin* research* or health research*).ti,ab

3. Models, Organisational/ or Models, Theory/ or Models, Theoretical/ or Systems Theory/ or (theor* or framework* or construct? or model* or concept ${ }^{*}$ ).ti,kw,kf. or (theor* or framework* or construct? or model* or concept* or heuristic* or lens or paradigm* or principle? or preengagement or phase? or stage? or "innovation support").ab

4. Health Planning/ or Health Systems / or Health Systems Plans/ or Organisation/ or Organisational Culture/ or Organisational Innovation/ or Organisational Objectives/ or Leadership/ or Governance/ or (system or systems or systemic or "health care" or "health administration" or (translat* or implement*)) or organisation*).ti,ab

5. 1 and (2 or 3$)$ and (3 or 4$)$ 


\section{Appendix 2}

Table 3 Excluded papers and reasons for exclusion

\begin{tabular}{|c|c|c|}
\hline Author,Year & Title & Reason excluded \\
\hline Borkowski, 2016 [17] & $\begin{array}{l}\text { Research culture in allied health: A systematic } \\
\text { review. Aust J Primary Health. 22(4):294-303. }\end{array}$ & $\begin{array}{l}\text { Not a framework; } \\
\text { enablers and barriers }\end{array}$ \\
\hline Byrne, 2014 [39] & $\begin{array}{l}\text { Developing a national mentorship scheme to } \\
\text { enhance the contribution of clinical academics } \\
\text { to health care. Nurs Res. 22(2): } 23-28 \text {. }\end{array}$ & $\begin{array}{l}\text { Not a framework; } \\
\text { enablers and barriers }\end{array}$ \\
\hline Cooke, 2008 [40] & $\begin{array}{l}\text { An evaluation of the 'Designated Research } \\
\text { Team' approach to building research capacity } \\
\text { in primary care. BMC Fam Pract. 9: } 37 \text {. }\end{array}$ & $\begin{array}{l}\text { Evaluation of framework } \\
\text { implementation }\end{array}$ \\
\hline Du Plessis, 2007 [64] & $\begin{array}{l}\text { Opinions on a strategy to promote nurses' } \\
\text { health research contribution in South Africa. } \\
\text { Health SA Gesondheid. 12(4):25-35. }\end{array}$ & $\begin{array}{l}\text { Not a framework; } \\
\text { Delphi study }\end{array}$ \\
\hline Elphinstone, 2015 [65] & $\begin{array}{l}\text { Untapped potential: Psychologists leading } \\
\text { research in clinical practice. Aust Psych. } \\
\text { 50(2): 115-121. }\end{array}$ & $\begin{array}{l}\text { Not a framework; research } \\
\text { capacity measurement }\end{array}$ \\
\hline Friesen, 2017 [66] & $\begin{array}{l}\text { Research culture and capacity in community } \\
\text { health services: Results of a structured survey }\end{array}$ & $\begin{array}{l}\text { Survey to inform enablers } \\
\text { and barriers }\end{array}$ \\
\hline
\end{tabular}

Frontera, 2006 [67] of staff. Aust J Prim Health. 23(2): 123-131.

Enablers and barriers

Gerrish, 2017 [33]

Rehabilitation Medicine Summit: Building Research Capacity: executive summary. Am J Occup Ther. 60(2):165-176.

Implementing clinical academic careers in nursing: an exemplar of a large healthcare organisation in the United Kingdom. J Res Nurs. 22(3):214-225.

Grange, 2005 [37]

Building research capacity. Nurs Manag (Harrow).12(7):32-37.

Holden, 2012 [27]

Evaluating a team-based approach to research capacity building using a matched-pairs study design. BMC Fam Pract.13:16.

Janssen, 2013 [68]

Building the research capacity of clinical physical therapists using a participatory action research approach. Phys Ther. 93(7): 923-34.

Joss, 2005 [69]

Workforce development to embed mental health promotion research and evaluation into organisational practice. Health Prom J Aust. 18(3): 255-259.

Judd, 2013 [70]

Building health promotion capacity in a primary health care workforce in the Northern Territory: some lessons from practice. Health Prom J Aust. 24(3):163-169.

Misso, 2016 [20]

Development, implementation and evaluation of a clinical research engagement and leadership capacity building program in a large Australian health care service. BMC Med Educ. 16: 13.

Moore, 2015 [71]

Council for allied health professions research: Collaborative initiative to develop and promote research capacity and influence. Physiother. 101, eS1027-eS1028.

Pickstone, 2008 [29]

Building research capacity in the allied health professions. Evidence Policy. 4(1): 53-68.

Probst, 2015 [36]

Research from therapeutic radiographers: An audit of research capacity within the UK. Radiography. 21(2):112-118.

Framework for career development and not research capacity

Not a framework; enablers and barriers

Not a framework; an intervention study

Not a framework; qualitative study of Physical Therapists

Not a framework

Not a framework; practitioner survey

Not a framework; Protocol for an intervention study

Conference abstract: no data

Not a framework

Not a framework; s urvey and audit

Not a framework; enablers and barriers 
Table 3 Excluded papers and reasons for exclusion (Continued)

\begin{tabular}{|c|c|c|}
\hline Author,Year & Title & Reason excluded \\
\hline Skinner, 2015 [35] & $\begin{array}{l}\text { Embedding research culture and productivity in } \\
\text { hospital physiotherapy departments: Challenges } \\
\text { and opportunities. Aust Health Rev. 39(3):312-314. }\end{array}$ & $\begin{array}{l}\text { Framework for translation; } \\
\text { not research capacity-building }\end{array}$ \\
\hline Varshney, 2016 [38] & $\begin{array}{l}\text { Understanding collaboration in a multi-national } \\
\text { research capacity-building partnership: a } \\
\text { qualitative study. Health Res Pol Syst.14: 1-10. }\end{array}$ & $\begin{array}{l}\text { Qualitative study; } \\
\text { enablers and barriers }\end{array}$ \\
\hline Wenke, 2016 [12] & $\begin{array}{l}\text { The role and impact of research positions within } \\
\text { health care settings in allied health: a systematic } \\
\text { review. BMC Health Serv Res. 16: } 355 \text {. }\end{array}$ & Not a framework \\
\hline Wenke, 2017 [14] & $\begin{array}{l}\text { Allied health research positions: a qualitative } \\
\text { evaluation of their impact. Health Res Pol } \\
\text { Syst. 15(1):6. }\end{array}$ & Not a framework \\
\hline Williams, 2015 [72] & $\begin{array}{l}\text { Research capacity and culture of the Victorian } \\
\text { public health allied health workforce is } \\
\text { influenced by key research support staff and } \\
\text { location. Aust Health Rev. 39(3):303-311. }\end{array}$ & $\begin{array}{l}\text { Not a framework; } \\
\text { investigation of } \\
\text { enablers and barriers }\end{array}$ \\
\hline
\end{tabular}

\section{Abbreviations}

CASP: Critical Appraisal Skills Programme; MMAT: Mixed Methods Appraisal Tool; PRISMA: Preferred Reporting Items for Systematic Reviews and MetaAnalyses

\section{Acknowledgments \\ Not applicable.}

\section{Funding}

SS and MM are supported by Healthscope and La Trobe University. KP is supported by the Victorian Department of Health and Human Services. The funders had no role in protocol development.

\section{Availability of data and materials}

All data generated or analysed during this study are included in this published article or are available from the first author on request.

\section{Authors' contributions}

The research question resulted from discussions among all the authors. The search strategies were developed with input from all authors. SS conducted the database searches and initial screening by title. SS and MM assessed the literature against the review criteria, and undertook data extraction, synthesis and analysis of the literature. All authors (SS, MM, KP) provided input into findings and conclusions and edited drafts of the article. All authors (SS, MM, $\mathrm{KP}$ ) read and approved the final manuscript.

\section{Ethics approval and consent to participate}

Not applicable.

\section{Consent for publication}

Not applicable.

\section{Competing interests}

The authors declare that they have no competing interests.

\section{Publisher's Note}

Springer Nature remains neutral with regard to jurisdictional claims in published maps and institutional affiliations.

\section{Author details}

'La Trobe Centre for Sport and Exercise Medicine Research, School of Allied Health, College of Science, Health \& Engineering, La Trobe University, Bundoora 3086, Australia. ${ }^{2}$ Department of Health and Human Services, Victoria State Government, 50 Lonsdale Street, Melbourne, Vic 3000, Australia. ${ }^{3}$ Healthscope, North Eastern Rehabilitation Centre, Ivanhoe, Australia.
Received: 13 November 2017 Accepted: 5 March 2018

Published online: 21 March 2018

\section{References}

1. Nancarrow SA, Young G, O'Callaghan K, Jenkins M, Philip K, Barlow K. Shape of allied health: an environmental scan of 27 allied health professions in Victoria. Aust Health Rev. 2017:41(3):327-35. https://doi.org/10.1071/ $\mathrm{AH} 16026$

2. Nancarrow SA, Roots A, Grace S, Moran AM, Vanniekerk-Lyons K. Implementing large-scale workforce change: learning from 55 pilot sites of allied health workforce redesign in Queensland, Australia. Human Res Health. 2013;11:66. https://doi.org/10.1186/1478-4491-11-66.

3. The Australian Government Department of Health. http//www.health.gov.au/ internet/publications/publishing.nsf/Content/work-review-australian-governmenthealth-workforce-programs-toc chapter-8-developing-dental-allied-healthworkforce chapter-8-allied-health-workforce. Accessed 15 Dec 2017.

4. Perry A, Morris M, Unsworth C, Duckett S, Skeat J, Dodd K, Taylor N, Reilly K Therapy outcome measures for allied health practitioners in Australia: the AusTOMs. Internat J Qual Health Care. 2004;16(4):285-91.

5. Nancarrow SA, Moran A, Sullivan R. Mechanisms for the effective implementation of an allied health assistant trainee: A qualitative study of a speech language pathology assistant. Aust Health Rev. 2015;39(1):101-8.

6. Harding KE, Porter J, Horne-Thompson A, Donley E, Taylor NF. Not enough time or a low priority? Barriers to evidence-based practice for allied health clinicians. J Contin Educ Heal Prof. 2014;34(4):224-31. https://doi.org/10. 1002/chp.21255

7. Stephens D, Taylor NF, Leggat SG. Research experience and research interests of allied health professionals. J Allied Health. 2009;38(4):e107-11.

8. Harding KE, Stephens D, Taylor NF, Chu E, Wilby A. Development and evaluation of an allied health research training scheme. J Allied Health. 2010:39(4):e143-8

9. Harding K, Lynch L, Porter J. Taylor NF Organisational benefits of a strong research culture in a health service: a systematic review. Aust Health Rev. 2017;41(1):45-53.

10. Haas R, Sarkies M, Bowles K-A, O'Brien L, Haines T. Early commencement of physical therapy in the acute phase following elective lower limb arthroplasty produces favourable outcomes: a systematic review and metaanalysis examining allied health service models. Osteoarthritis Cartil. 2016; 24(10):1667-81. https://doi.org/10.1016/j.joca.2016.05.005

11. Philip K. Allied health: untapped potential in the Australian health system. Aust Health Rev. 2015;39(3):244-7.

12. Wenke $\mathrm{R}$, Mickan $\mathrm{S}$. The role and impact of research positions within health care settings in allied health: a systematic review. BMC Health Serv Res. 2016:16:355. https://doi.org/10.1186/s12913-016-1606-0

13. Sackett DL, Rosenberg W, McGray JA, Haynes RB, Richardson WS. Evidencebased medicine: what it is and what it isn't. BMJ. 1996:312:71-2. doi.org/10. 1136/bmj.312.7023.71 
14. Wenke RJ, Mickan S, Bisset L. A cross sectional observational study of research activity of allied health teams: is there a link with self reported success, motivators and barriers to undertaking research? BMC Health Serv Res. 2017:17:114.

15. Dizon JMR, Grimmer-Somers KA, Kumar S. Current evidence on evidencebased practice training in allied health: a systematic review of the literature. Int J Evid Based Healthc. 2012;10:347-60.

16. Stephens D, Taylor NF, Taylor N, et al. Research experience and research interests of allied health professionals. J Allied Health. 2009;38:e107-11.

17. Borkowski D, McKinstry C, Cotchett M, Williams C, Haines T. Research culture in allied health: A systematic review. Aust J Primary Health. 2016;22(4):294-3. https://doi.org/10.1071/PY15122.

18. Rastrick S. AHPs into Action: Using Allied Health Professionals to Transform Health, Care and Wellbeing. 2017. https://www.england.nhs.uk/ourwork/ qual-clin-lead/ahp. Accessed 15 Dec 2017

19. Farmer E, Weston K. A conceptual model for capacity building in Australian primary health care research. Aust Fam Phys. 2002;31(12):1139-42.

20. Misso ML, Ilic D, Haines TP, Hutchinson AM, East CE, Teede HJ. Development, implementation and evaluation of a clinical research engagement and leadership capacity building program in a large Australian health care service. BMC Med Educ. 2016;16:13. https://doi.org/10.1186/ s12909-016-0525-4

21. Dimond EP, Germain DS, Nacpil LM, Zaren HA, et al. Creating a "culture of research" in a community hospital: Strategies and tools from the National Cancer Institute Community Cancer Centers Program. Clin Trials. 2015;12(3): 246-56. https://doi.org/10.1177/1740774515571141

22. Redman S, Turner T, Davies H, Williamson A, et al. The SPIRIT Action Framework: a structured approach to selecting and testing strategies to increase the use of research in policy. Soc Sci Med. 2015:147-55. https://doi. org/10.1016/j.socscimed.2015.05.009

23. NSW Health. A Framework for Building Capacity to Improve Health. Better Health Centre - Publications Warehouse. Locked Mail Bag 5003 Gladesville, NSW 2111. 2001. www.health.nsw.gov.au. Accessed 15 Dec 2017.

24. Hotte N, Simmons L, Beaton K, the LDCP Workgroup. Scoping Review of Evaluation Capacity Building Strategies. Cornwall; 2015. https://www. publichealthontario.ca/en/eRepository/Scoping_Review_Evaluation_ Capacity_LDCP_2015.pdf. Accessed 15 Dec 2017.

25. Golenko X, Pager S, Holden L. A thematic analysis of the role of the organisation in building allied health research capacity: a senior managers' perspective. BMC Health Serv Res. 2012;12:276. https://doi.org/10.1186/1472-6963-12-276

26. Cooke J. A framework to evaluate research capacity building in health care. BMC Fam Pract. 2005;6:11. https://doi.org/10.1186/1471-2296-6-44

27. Holden L, Pager S, Golenko X, Ware RS. Validation of the research capacity and culture (RCC) tool: measuring RCC at individual, team and organisation levels. Aust J Primary Health. 2012;18(1):62-7. https://doi.org/10.1071/PY10081

28. Hulcombe J, Sturgess J, Souvlis T, Fitzgerald C. An approach to building research capacity for health practitioners in a public health environment: an organisational perspective. Aust Health Rev. 2014;38(3):252-8. https://doi. org/10.1071/AH13066

29. Pickstone C, Nancarrow S, Cooke J, Vernon W, Mountain G, Boyce R, Campbell J. Building research capacity in the allied health professions. Evid Policy. 2008;4(1):53-68. https://doi.org/10.1332/174426408783477864.

30. Whitworth A, Haining S, Stringer $H$. Enhancing research capacity across healthcare and higher education sectors: development and evaluation of an integrated model. BMC Health Serv Res. 2012;12:287. https://doi.org/10. 1186/1472-6963-12-287

31. O'Byrne L, Smith S. Models to enhance research capacity and capabilities in clinical nurses: a narrative review. J Clin Nurs. 2011;20(9-10):1365-71. https://doi.org/10.1111/j.1365-2702.2010.03282.x

32. Segrott J, Mclvor M, Green B. Challenges and strategies in developing nursing research capacity: a review of the literature. Intern J Nurs Stud. 2006:43(5):637-51.

33. Gerrish $\mathrm{K}$, Chapman $\mathrm{H}$. Implementing clinical academic careers in nursing: an exemplar of a large healthcare organisation in the United Kingdom. J Res Nurs. 2017;22(3):214-25. https://doi.org/10.1177/1744987116689133.

34. Wenke RJ, Ward EC, Hickman I, Hulcombe J, Phillips R, Mickan S. Allied health research positions: a qualitative evaluation of their impact. Health Res Policy Syst. 2017;15:6. https://doi.org/10.1186/s12961-016-0166-4.

35. Skinner EH, Williams CM, Haines TP. Embedding research culture and productivity in hospital physiotherapy departments: Challenges and opportunities. Aust Health Rev. 2015;39(3):312-4.
36. Probst $H$, Harris R, McNair HA, Baker A, Miles EA, Beardmore C. Research from therapeutic radiographers: An audit of research capacity within the UK. Radiography. 2015;21(2):112-8. https://doi.org/10.1016/j.radi.2014.10.009.

37. Grange A, Herne S, Casey A, Wordsworth L. Building research capacity. Nurs Manag (Harrow). 2005;12(7):32-7.

38. Varshney D, Atkins S, Das A, Diwan V. Understanding collaboration in a multinational research capacity-building partnership: a qualitative study. Health Res Policy Syst. 2016;14:64. https://doi.org/10.1186/s12961-016-0132-1.

39. Byrne G, Topping A, Kendall S, Golding B. Developing a national mentorship scheme to enhance the contribution of clinical academics to health care. Nurs Res. 2014;22(2):23-8. https://doi.org/10.7748/nr.22.2.23.e1288

40. Cooke J, Nancarrow S, Dyas J, Williams M. An evaluation of the 'Designated Research Team' approach to building research capacity in primary care. BMC Fam Pract. 2008;9:37. https://doi.org/10.1186/1471-2296-9-37.

41. Higgins JP, Green S. Cochrane Handbook for Systematic Reviews of Interventions. Chichester: Wiley Online Library; 2011.

42. Feathersone RM, Dryden DM, Foisy M, Guise JM, Mitchell MD, Paynter RA, Robinson KA, Umscheid CA, Hartling L. Advancing knowledge of rapid reviews: an analysis of results, conclusions and recommendations from published review articles examining rapid reviews. Syst Rev. 2015;4:50. https://doi.org/10.1186/s13643-015-0040-4.

43. Thomas J, Newman M, Oliver S. Rapid evidence assessments of research to inform social policy: taking stock and moving forward. Evid Policy. 2013;9:527. https://doi.org/10.1332/174426413X662572.

44. Moher D, Liberati A, Tetzlaff J, Altman DG. Preferred reporting items for systematic review and meta-analyses: the PRISMA statement. BMJ. 2009;339: 332-6. https://doi.org/10.1371/journal.pmed.1000097.

45. Tong A, Flemming K, Mclnnes E, Oliver SA, Craig J. Enhancing transparency in reporting the synthesis of qualitative research: ENTREQ. BMC Med Res Methodol. 2012;12:181. https://doi.org/10.1186/1471-2288-12-181.

46. Oxford Dictionary. Theory. https://en.oxforddictionaries.com/definition/ theory. Accessed 15 Dec 2017

47. Nilsen P. Making sense of implementation theories, models and frameworks Implement Sci. 2015;10:53. https://doi.org/10.1186/s13012-015-0242-0

48. Pace R, Pluye P, Bartlett G, Macaulay AC, Salsberg J, Jagosh J, Seller R. Testing the reliability and efficiency of the pilot Mixed Methods Appraisal Tool (MMAT) for systematic mixed studies review. Internat J Nurs Studies. 2012;49(1):47-53. https://doi.org/10.1016/j.ijnurstu.2011.07.002

49. CASP. Critical Skills Appraisal Programme: 10 Questions to Help you Make Sense of Qualitative Research. Milton Keynes: Milton Keynes Primary Care Trust; 2002.

50. The National Collaborating Centre for Methods and Tools. http://www. nccmt.ca/. Accessed 15 Dec 2017

51. Miles M, Huberman AM, Saldaña J. Qualitative Data Analysis: A Methods Sourcebook. 3rd ed. Los Angeles: Sage; 2014.

52. Strauss A, Corbin J. Basics in Qualitative Research: Techniques and Procedures for Developing Grounded Theory. 2nd ed. Thousand Oaks: Sage Publications; 1998.

53. Charmaz K. Constructing Grounded Theory: A Practical Guide Through Qualitative Analysis. Thousand Oaks: Sage Publications Inc.; 2006.

54. Brennan SE, McKenzie JE, Turner T, Redman S, Makkar S, Williamson A Haynes A, Green SA. Development and validation of SEER (Seeking, Engaging with and Evaluating Research): a measure of policymakers' capacity to engage with and use research. Health Res Policy Syst. 2017;15:1. https://doi.org/10.1186/s12961-016-0162-8

55. Fleisher L, Kornfeld J, Davis S, Morra ME, Squiers L. The NCl's Cancer Information Services Research Continuum Framework: integrating research into cancer education practice (1999-2004). J Cancer Educ. 2007;22:S41-8.

56. Gullick JG, West SH. Building research capacity and productivity among advanced practice nurses: an evaluation of the Community of Practice model. J Adv Nurs. 2016;72(3):605-19. https://doi.org/10.1111/jan.12850

57. McCance TV, Fitzsimons D, Armstrong NC. Developing a best practice framework to benchmark research and development activity in nursing and midwifery. J Res Nurs. 2006;11(2):160-71. https://doi.org/10.1177/ 1744987106062839

58. Makkar SR, Turner T, Williamson A, Louviere J, Redman S, Haynes A, Green S, Brennan S. The development of ORACLe: a measure of an organisation's capacity to engage in evidence-informed health policy. Health Res Policy Syst. 2016;14:4. https://doi.org/10.1186/s12961-015-0069-9

59. Makkar SR, Brennan S, Turner T, Williamson A, Redman S, Green S. The development of SAGE: A tool to evaluate how policymakers' engage with 
and use research in health policymaking. Res Eval. 2016;25(3):315-28. https://doi.org/10.1093/reseval/rvv044.

60. Ried K, Farmer EA, Weston KM. Setting directions for capacity building in primary health care: a survey of a research network. BMC Fam Pract. 2006;7:8. https://doi.org/10.1186/1471-2296-7-8.

61. The National Institute for Health and Care Excellence. https://www.nice.org. uk/guidance. Accessed 15 Dec 2017.

62. The Australian Health Practitioner Regulation Agency. https://www.ahpra. gov.au/. Accessed 15 Dec 2017.

63. Oliver K, Innvar S, Lorenc T, Woodman J, Thomas J. A systematic review of barriers to and facilitators of the use of evidence by policymakers. BMC Health Serv Res. 2014;14:2. https://doi.org/10.1186/1472-6963-14-2

64. Du Plessis D, Human SP. Opinions on a strategy to promote nurses' health research contribution in South Africa. Health SA Gesondheid. 2007;12(4):25-35.

65. Elphinstone RA, Pager S. Untapped potential: Psychologists leading research in clinical practice. Aust Psych. 2015;50(2):115-21.

66. Friesen EL, Comino EJ. Research culture and capacity in community health services: Results of a structured survey of staff. Aust J Prim Health. 2017; 23(2):123-131.

67. Frontera WR, Fuhrer MJ, Jette AM, Chan L, Cooper RA, Duncan PW, et al. Rehabilitation Medicine Summit: Building Research Capacity: executive summary. Am J Occup Ther. 2006;60(2):165-76.

68. Janssen J, Hale L, Mirfin-Veitch B, Harland T. Building the research capacity of clinical physical therapists using a participatory action research approach. Phys Ther. 2013;93(7):923-34.

69. Joss $\mathrm{N}$, Keleher H. Workforce development to embed mental health promotion research and evaluation into organisational practice. Health Prom J Aust. 2005;18(3):255-9.

70. Judd J, Keleher H. Building health promotion capacity in a primary health care workforce in the Northern Territory: some lessons from practice. Health Prom J Aust. 2013;24(3):163-9.

71. Moore A, Gosling S, Fitch F. Council for allied health professions research: Collaborative initiative to develop and promote research capacity and influence. Physiother. 2015;101:eS1027-eS1028.

72. Williams C, Miyazaki K, Borowski D, McKinstry C, Cotchet M, Haines T. Research capacity and culture of the Victorian public health allied health workforce is influenced by key research support staff and location. Aust Health Rev. 2015;39(3):303-11.

\section{Submit your next manuscript to BioMed Central and we will help you at every step:}

- We accept pre-submission inquiries

- Our selector tool helps you to find the most relevant journal

- We provide round the clock customer support

- Convenient online submission

- Thorough peer review

- Inclusion in PubMed and all major indexing services

- Maximum visibility for your research

Submit your manuscript at www biomedcentral.com/submit

) Biomed Central 